\title{
Optimal Retail Price Model for Partial Consignment to Multiple Retailers
}

\author{
Po-Yu Chen \\ Department of Advertising and Strategic Marketing, Ming Chuan University, No. 250 Zhong Shan N. Rd., Sec. 5, Taipei, Taiwan \\ Correspondence should be addressed to Po-Yu Chen; chenboy@mail.mcu.edu.tw
}

Received 19 August 2017; Revised 16 November 2017; Accepted 4 December 2017; Published 31 December 2017

Academic Editor: Borja Ponte

Copyright (c) 2017 Po-Yu Chen. This is an open access article distributed under the Creative Commons Attribution License, which permits unrestricted use, distribution, and reproduction in any medium, provided the original work is properly cited.

\begin{abstract}
This paper investigates the product pricing decision-making problem under a consignment stock policy in a two-level supply chain composed of one supplier and multiple retailers. The effects of the supplier's wholesale prices and its partial inventory cost absorption of the retail prices of retailers with different market shares are investigated. In the partial product consignment model this paper proposes, the seller and the retailers each absorb part of the inventory costs. This model also provides general solutions for the complete product consignment and the traditional policy that adopts no product consignment. In other words, both the complete consignment and nonconsignment models are extensions of the proposed model (i.e., special cases). Research results indicated that the optimal retail price must be between $1 / 2(50 \%)$ and $2 / 3(66.67 \%)$ times the upper limit of the gross profit. This study also explored the results and influence of parameter variations on optimal retail price in the model.
\end{abstract}

\section{Introduction}

Advancements in information technology have changed product transaction process. The transaction process from sellers (upstream suppliers; suppliers) toward buyers (downstream vendors; retailers) has been partially replaced by ecommerce tools and logistics services. In the transaction process, most transaction costs are related to providing product information and convenient product access to the consumer. The use of e-commerce tools can reduce negotiation, ordering, and payment costs during the transaction process. The convenience of logistics services can reduce transaction costs. Although e-commerce improves transaction efficiency, not all goods are suitable for online transactions, particularly those that consumers must touch, observe, and "try out" in order to confirm the function or quality of the product before a purchase can be made at ease. In such transactions, the type of sales channel is a critical factor. We assumed that for certain types of goods, suppliers provide the goods and retailers provide a sales channel. Only through cooperation can the suppliers and retailers promote the goods and sell them to consumers. Regarding the selling of goods, cooperation between suppliers and retailers is effectively a form of partnership rather than a completely transaction-oriented relationship. In a retail sales channel, when a consumer purchases consigned goods from a retailer (the sales price is determined by the supplier), the retailer must immediately pay a consignment percentage to the supplier. The consignment percentage is stipulated in an advance pricing agreement between the retailer and the supplier. From the perspective of the retailer, the profits from consignment sales are regarded as rental income for providing a sales channel; however, such income is not paid periodically and the amount paid is not fixed. This situation is not only ongoing, but the level of income changes with the sales rate.

The aforementioned trading patterns raise the following three questions: In what type of industrial environment or under what policy is it appropriate for suppliers and retailers to form a partnership to enhance product sales collaboratively? Who should initiate or establish such partnerships? Who should supervise the partnership to ensure that the parties honor the contract, and who should monitor and control the supplier to ensure its stability? Addressing these three questions simultaneously requires considering the involved suppliers, retailers, and financial institutes.

Partnerships between suppliers and retailers are particularly crucial for developing Taiwan's industries. According to the statistics of the Small and Medium Enterprise 
Administration (MOEA-SMEA) [1], 97.73\% of all enterprises in Taiwan are small and medium-sized enterprises (SMEs). In the manufacturing sector as well as the wholesale and retail trade sector, $96.12 \%$ and $97.55 \%$ are SMEs, respectively. In this industrial environment, most enterprises in Taiwan are small and medium-sized enterprises that cannot provide sufficient collateral for bank loans. Consequently, economic development in Taiwan has effectively been restricted because the banks provide limited funds to assist enterprises in investment, research and development, and innovation. The aforementioned consignment model seems complex (involving both supplier and retailers), but the key is who supervises the retailer to ensure that they pay the agreed percentage immediately to the supplier in accordance with the advance pricing agreement? We recommend that such a transaction pattern be operated through the assistance of banking institutions or third party payment platforms, which has particular implications in Taiwan's retail industry.

From a supply chain perspective, the retailers' profit (the relationship between product price and cost) is closely related to that of their suppliers. Thus, the relationship between suppliers and retailers is increasingly being valued. A superior partnership can not only reduce uncertainties in the supply chain, but also enable retailers to play a crucial role in a successful supply chain system. In recent years, suppliers have shifted from employing their traditional policies (TPs) to adopting consignment policies (CPs). Such shifting has become a popular trend, in which suppliers cosign their goods to multiple retailers. The operation pattern of suppliers and retailers working individually has transformed into a pattern involving bilateral cooperation. This is a common consignment channel used by Watsons in Asia, 7-11 in the United States, Melissa and Doug, and numerous corner shops. The definition of consignment, according to the American Production and Inventory Control Society (APICS), is "the process of a supplier placing goods at a customer location without receiving payment until after the goods are used or sold."

The following are the advantages of consigning products to multiple retailers:

(a) The rent for the sales location and insurance costs are absorbed by the retailer.

(b) Reputable or trustworthy consignment retailers can be selected to establish long-term relationships.

(c) When popular sales locations change with the environment, suppliers can rapidly adjust sales locations to increase flexibility.

(d) Suppliers can increase the quantity of products on the shelves by consigning to multiple retailers, and the quantity of products available on shelves for viewing by consumers is an essential indicator in product visibility.

(e) Suppliers can understand the market distribution of products by using Electronic Data Interchange (EDI) to contact retailers.

(f) Suppliers can obtain real-time product sales reports from retailers, which enables suppliers to actively respond to changes in consumer product preferences. (g) Suppliers can use advantageous inventory management and transportation strategies to maintain adequate supplies among retailers.

(h) It reduces suppliers' costs caused by obsolete products.

The advantages for retailers accepting supplier-consigned products are as follows:

(a) Reduces tied up inventory capital and improves cash flow.

(b) Reduces losses from returns and exchanges because of insufficient consumer awareness regarding product attributes, such as changes in product size, form, or color.

(c) Buyer (retailer) transaction costs (such as sellers delivering the products to the retail store) are absorbed by the sellers (main supplier).

(d) Retailers that use e-commerce platforms (Web-based transactions) for retail sales can guarantee that they transfer payment to suppliers only after consumers have received their products. Because e-commerce transaction methods use banks as a third party guarantor, transaction disputes as a result of insufficient consumer awareness toward product information can be reduced.

(e) Improves retailer service levels (reduces risk of being out of stock).

(f) The retailers can reduce the inventory cost of unsold goods resulting from changes in consumer preferences or from products having an extremely short life cycle. Moreover, the losses incurred from unsold goods can be reduced, and high-demand products or those that meet the needs of consumers can be made available for purchase within a relatively short time. Nonetheless, the effect of the cooperative consignment strategy is determined by the completeness of the consignment condition.

Over the past decade, numerous studies have been conducted on consignment stocks (CSs) and have made great contributions to integrating the supplier-buyer supply chain. These studies include Zavanella and Zanoni [2], Battini et al. [3], Srinivas and Rao [4], Yu et al. [5], Ben-Daya et al. [6], Hariga and Al-Ahmari [7], Sarkar [8], Singh et al. [9], Islam et al. [10], and Zahran and Jaber [11]. Studies have mainly considered the optimal consignment models regarding the whole supply chain or investigated the optimal consignment decisions from the perspectives of single suppliers or of retailers. However, they have rarely discussed the inventory risk costs in terms of which parties should absorb them (the supplier alone or both the supplier and the retailers). More importantly, most studies have overlooked the fact that retailers are competitors. Their competition is mainly reflected in the retail prices of their goods. How a retailer decides on optimal retail prices is closely related to the retailer's upper limit of the gross profit. Given Taiwan's industry background and the aforementioned reasons, the present study considers 
how a supplier's partial absorption of inventory costs affects the retail prices set by multiple suppliers with different market shares. This is the main characteristic of the mathematical model this study proposes, marking the major difference between this model and other CS models.

The rest of this paper is arranged as follows. Section 2 explores relevant studies on CS and highlights the characteristics of the proposed model and how it differs from other models. In Section 3, the symbols and assumptions of this model are defined. The mathematical model is described in Section 4, and sensitivity analyses are detailed in Section 5. Section 6 provides our conclusions and highlights the findings and their managerial implications.

\section{Supply Chain Problems}

Numerous studies have been conducted on supply chain problems between buyers and sellers. Goyal $[12,13]$ proposed the joint economics lot size (JELS) model for solving total cost minimization problems between suppliers and buyers. In their studies on the promotion of the JELS model, Goyal [14] and Goyal and Gupta [15] relaxed the assumed condition that suppliers use lot sales to improve the practicality of the model. However, these models all assumed that both suppliers and buyers were willing to accept this type of structured arrangement, which does not conform to actual practice.

In reality, the economic order quantity encountered by suppliers and retailers may be different. Thus, suppliers and retailers must negotiate product unit price and lot quantity. The aforementioned optimal arrangement from supplier and retailer negotiation is not the optimal arrangement for either the supplier or the retailer [16].

2.1. Single-Supplier, Single-Buyer. In a single-supplier, singlebuyer integrated inventory model, Hill $[17,18]$ discovered (under the assumption that buyer demand and ordering frequency is known) that the average total cost per unit time in a supplier and buyer cooperative relationship is far lower than when both parties do not cooperate. Goyal [19] further considered the influence of limitations in transportation equipment volume on the integrated model. Other related research focused on relaxing the assumed conditions to improve the applicability of the integrated inventory model [20-22]. Valentini and Zavanella [23] described the advantages of consignment stock (CS) strategy. Suppliers can not only use the storage space of buyers, but also avoid temporary large quantity orders from buyers. This enables suppliers to conduct product management that is most advantageous to themselves. Buyers can also maintain a basic stock level and improve service levels (reduce risks of being out of stock).

Braglia and Zavanella [24] proposed a CS strategy analysis model for a single-supplier and single-buyer in an uncertain environment (delayed delivery and random market demand). Zanoni and Grubbstrom [25] promoted a model by Braglia and Zavanella [24], which considered the optimization of quantity transported, number of deliveries, and delayed deliveries. The CS analysis model developed by Srinivas and Rao [26] considered the contractual and crashing costs of lead time. In their CS analysis model, Persona et al. [27] considered the risks of obsolete products. Hill and Omar [28] compiled the aforementioned single-supplier, singlebuyer integrated product inventory problems. Using CS as an example, they allowed different lot quantities for each purchase and proposed a solution [29]. Gümüş et al. [30] discussed the influence of consignment storage and supplier inventory management. Ru and Wang [31] and Hwang and Wan [32] compared the profits and losses of retailer-managed consignment and supplier-managed consignment. Wang et al. [33] proposed a consignment inventory model of deteriorating products for buyers with storage limitations. Islam and Hoque [34] considered the optimal consignment inventory strategy for product demand distribution.

These studies typically explored problems in a singlesupplier, single-buyer inventory system, and these research results cannot be generalized to single-supplier, multiplebuyer inventory management problems. The primary reason for this limitation is the assumption that suppliers' production strategies are not influenced by buyers' purchase quantity. In reality, the buyers' purchase quantity not only influences the income of suppliers, but also influences production costs. This influence grows when a supplier encounters multiple buyers [35, 36]. However, a competitive relationship exists between buyers and they will use the product management strategies that are most advantageous to themselves [37].

2.2. Single-Supplier, Multiple-Buyer. Numerous single-supplier, multiple-buyer integrated inventory analysis models have been proposed; however, these integrated inventory models do not discuss consignment inventory problems $[8,38-46]$. Yet, a few of the perspectives are noteworthy: Woo et al. [40] indicated that all suppliers and buyers are willing to establish EDI systems to reduce ordering costs. Furthermore, suppliers can grasp the real-time sales situation of buyers and modify their decision systems [16]. Siajadi et al. [47] discussed supplier product-transportation strategies and indicated that suppliers who transport products to multiple buyers obtain more profits than those who transport products to a single-buyer. This difference resulted from the fact that suppliers effectively establish transportation strategies and reduce transaction costs [48]. In their literature review, Chen and Sarker [46] underlined that the integrated model of integrated pricing and build to stock has gradually gained the attention of academia.

In a study on single-supplier, multiple-buyer integrated consignment inventory, Piplani and Viswanathan [49] developed a performance assessment model for traditional policy (TP) and consignment policy (CP). Srinivas and Rao [4, 50] used a genetic algorithm to develop a consignment inventory optimization model. Zavanella and Zanoni [2] built a singlesupplier, multiple-buyer integrated product inventory model based on CS. Yu et al. [5] used a simulation method to compare the potential profits of suppliers who used TP and CP. They discovered that suppliers using CP obtained a higher profit than those who used TP. Battini et al. [3] developed a multi-echelon inventory system for a singlesupplier and multiple buyers. Islam et al. [10] proposed a single-supplier, single-vendor, multiple-buyer product 
consignment inventory model and discovered that using CP increased the profits of consignment partners. Ben-Daya et al. [6] built a seller management consignment inventory model. Zahran and Jaber [11] further compared the profit differences among models adopting only TP or CP or integrated models adopted both at the supplier-vendor and vendor-retailer levels. Other studies on single-supplier, multiple-buyer CS management primarily relaxed assumption conditions to consider environmental limitations in actual practice, or included product demand distribution into the considerations [7-9, 51-54]. Sarker [55] categorizes the consignment inventory model by structural configuration of the systems, operational policies, component analyses, cost and profit, and several other standard measures.

However, the focus of these research models was the contribution of consignment inventory toward the overall supply chain or to discuss optimal decisions in consignment inventory from the perspective of suppliers or retailers. These studies overlooked the fact that retailers must frequently adjust sale prices and irregularly promote the sales of product combinations when they encounter market competition. Few previous studies on consignment models have not discussed complete consignment models, in which the supplier absorbs the risk cost to retailers for failing to sell products, as well as partial consignment models, in which both suppliers and retailers absorb a part of the risk cost. Thus, the use of previous integrated consignment inventory models on these practical applications is limited.

Additionally, retailers have a competitive relationship, especially in a maturing e-commerce environment. Neither a consignment inventory system that considers the optimal decision of various retailers nor consignment inventory decisions that include product demand distribution problems can reflect the order decisions of retailers in a competitive relationship. Discussing the order decisions of retailers from the perspective of market share rate is highly relevant to the market situation and can increase the applicability of the results.

The primary feature of the transaction model proposed in this paper is that financial institutions are given adequate control over the transactions between suppliers, retailers, and consumers. If the suppliers obtain bank funds in installments for production purposes in accordance with a loan plan and then supply goods to the retailers through a sales channel affiliated with the bank, then the bank can easily determine whether the conversion of loaned funds into goods is as planned. In addition, a portion of the profits generated through the sale of goods under the proposed model can contribute to ongoing loan repayments as per the agreement. Therefore, the three questions inferred from a partial consignment model are echoed: (1) In an industrial environment a high percentage of enterprises are SMEs or enterprises often cannot provide sufficient collateral to gain bank loans, (2) suppliers or financial institutes can take the initiative and propose partnerships between suppliers and retailers, and (3) financial institutes may play the role of supervisors to ensure that the partnership is carried out according to their contracts and that the supplier stably provides supplies. The main negotiation when the supplier and multiple retailers make a contract will lie in the ratio at which each party undertakes the inventory costs. The proposed model has attracted considerable attention from the business sector and banking industry in Taiwan. The primary purpose of this study is to promote the proposed transaction model at all social levels in Taiwan, thereby achieving a mutually beneficial outcome for all parties (suppliers, retailers, and the banking industry). This is also the main difference between the proposed model and past CS models.

This paper examined the suppliers consignment strategies based on the assumption that the retailers agree to a partial consignment transaction model. The model in this study is for a single-supplier consigning products to multiple retailers, and the pricing decision for a single product was considered. The decision makers for pricing can be divided into a singlesupplier and multiple retailers. When the supplier deals with multiple retailers, each retailer adopts an economic order quantity (EOQ) decision model that minimizes each cycle's total cost (the sum of ordering costs and inventory costs) according to its market share (sales quantity per unit time). This study's mathematical model examines how, given that the supplier partially absorbs the inventory costs of the multiple retailers (i.e., the retailers only need to pay part of the wholesale price to the supplier when placing orders and can pay the rest after the retail sale is complete), the wholesale price and the partial absorption of inventory costs affect the retail prices of multiple retailers with different market shares.

\section{Symbols and Assumptions}

This study uses capitalized English characters to represent functions and lower case English characters to represent the constants.

$p$ : the price at which suppliers sell products to retailers (the wholesale price), where $p>c>0$.

c: cost per unit product obtained by suppliers.

$e$ : the cost per unit the retailer immediately pays the supplier upon buying the product, where $p \geq e \geq 0$.

$(p-e)$

is the remaining amount the retailers delay in paying the supplier until a product they have purchased is sold to the consumer.

When $e=0$, the supplier adopts the strategy of complete consignment: the retailers only pay the supplier after they finish selling the products to customers.
When $e<p$, the supplier adopts a partial consignment strategy. In that case, usually the supplier must pay rack fees in advance, such as a fixed amount of 
money or a certain percentage of the agreed sales price specified in a contract. When $e=p$ the supplier and retailers adopt the $\mathrm{TP}$ in which the retailers buy out the goods. In the complete consignment model, the risk cost of unsold goods is absorbed by the retailer, whereas that in the partial consignment model is absorbed by both the supplier and the retailer.

Because supplier adopting complete consignment model is a special case of this study, the general characteristics of this study results in the complete consignment model still hold.

$a$ : the fixed transaction cost (i.e., the setup cost) of each retailer for each purchase (cost $a$ is produced with each purchase regardless of purchase quantity).

$s$ : the cost of ownership per unit capital in each unit time.

$h$ : retailers' cost of ownership per unit product in each unit time can be assumed from (1):

$$
h=e \cdot s .
$$

$n$ : number of retailers.

$v_{i}$ : the $i$ th retailers' gross profit for each unit product, that is, the difference between the retailers' retail price $\left(p+v_{i}\right)$ and purchase price $p ; v_{i}$ value is the retailers' decision variable, which differs with each retailer.

$v_{i}^{*}$ : the gross profit of maximized unit time profit for retailer $i$.

The optimized retail price for retailer $i$ is $\left(p+v_{i}^{*}\right)$.

$\theta_{i}$ : the market share of retailer $i$, where

$$
\begin{aligned}
0 & <\theta_{n} \leq \theta_{n-1} \leq \cdots \leq \theta_{1}, \\
\sum_{i=1}^{n} \theta_{i} & =1 .
\end{aligned}
$$

$\bar{r}$ : the upper limit for consumer market demand rate (demand rate when sales price $\left(p+v_{i}\right)$ is 0$)$.

$R$ : sales rate per unit time (sales quantity per unit time) for retail price $\left(p+v_{i}\right)$, where

$$
R\left(p+v_{i}\right)=\bar{r}-l\left(p+v_{i}\right), \quad i=1,2, \ldots, n .
$$

$l$ : the rate of change for sales price and unit time sales quantity in the consumer market, where $\bar{r} / l$ is the upper limit of the sales price in the consumer market. When the sales price $\left(p+v_{i}\right)$ increases to $\bar{r} / l$, the demand rate is 0 (as shown in (5)). Therefore,

$\left(\frac{\bar{r}}{l}-p\right)$ is the upper limit for gross profit $v_{i}$, $r_{i}$ : the sale quantity of retailer $i$ per unit time. When the retail price is $\left(p+v_{i}\right)$, the retailer sales quantity per unit time $\left(r_{i}\right)$ is the sales rate per unit time $(R)$ (as shown in (5)) multiplied by the market share of retailer $\theta_{i}$ :

$$
r_{i}=\theta_{i}\left[\bar{r}-l\left(p+v_{i}\right)\right] .
$$

\section{Mathematical Model}

Providing that $n$ retailers using EOQ purchase decision exist and that they all purchase from the same supplier, the situation encountered by each retailer is as follows.

4.1. Retailer's Optimal Purchase Cycle and Optimal Purchase Quantity. The optimal solution from the EOQ model showed that when the sales price of retailer $i$ is $\left(p+v_{i}\right)$, the optimal purchase cycle $t_{i}$ and the optimal purchase quantity $q_{i}$ for each cycle are as follows [56]:

$$
\begin{aligned}
t_{i} & =\sqrt{\frac{2 \cdot a}{h \cdot r_{i}}}=\sqrt{\frac{2 \cdot a}{e \cdot s \cdot \theta_{i}\left[\bar{r}-l\left(p+v_{i}\right)\right]}}, \\
q_{i} & =\sqrt{\frac{2 \cdot a \cdot \theta_{i}\left[\bar{r}-l\left(p+v_{i}\right)\right]}{e \cdot s}} .
\end{aligned}
$$

4.2. The Maximal Unit Time Profit $\pi_{i}$ of Retailer $i$. From (7), the unit time income of retailer $i$ can be obtained:

$$
\left(p+v_{i}\right) r_{i}=\left(p+v_{i}\right) \cdot \theta_{i}\left[\bar{r}-l\left(p+v_{i}\right)\right] .
$$

From (7) and (8), when the gross profit for the $i$ th retailer is $v_{i}$, the cost of ownership per unit inventory in each unit time for the retailer $i$ is

$$
\begin{aligned}
\frac{1}{t_{i}}\{a+ & \left.p \cdot \theta_{i}\left[\bar{r}-l\left(p+v_{i}\right)\right] \cdot t_{i}+\frac{1}{2} e s \cdot q_{i} t_{i}\right\} \\
= & \sqrt{\frac{e s \cdot \theta_{i}\left[\bar{r}-l\left(p+v_{i}\right)\right]}{2 a}} \cdot a+p \\
& \cdot \theta_{i}\left[\bar{r}-l\left(p+v_{i}\right)\right] \\
& +\frac{1}{2} e s \sqrt{\frac{2 a \cdot \theta_{i}\left[\bar{r}-l\left(p+v_{i}\right)\right]}{e \cdot s}} \\
= & \sqrt{2 a e s \cdot \theta_{i}\left[\bar{r}-l\left(p+v_{i}\right)\right]}+p \\
& \cdot \theta_{i}\left[\bar{r}-l\left(p+v_{i}\right)\right] .
\end{aligned}
$$

From (10), when the values of $p$ and $e$ are given by the supplier, the maximal unit time profit $\pi_{i}$ of retailer $i$ is

$$
\begin{aligned}
\max _{0 \leq v_{i} \leq \bar{r} / l-p} \pi_{i}= & v_{i} \theta_{i}\left[\bar{r}-l\left(p+v_{i}\right)\right] \\
& -\sqrt{2 a e s \cdot \theta_{i}\left[\bar{r}-l\left(p+v_{i}\right)\right]} \\
& \\
i=1,2, \ldots, n . &
\end{aligned}
$$


4.3. Optimal Solution $v_{i}$ of (11). Let $v_{i}^{*}$ be the optimal solution for (11). Consider the derivative of $\pi_{i}$ with respect to $v_{i}$ to obtain

$$
\begin{aligned}
& \frac{d \pi_{i}}{d v_{i}}=\theta_{i}\left[\bar{r}-l\left(p+v_{i}\right)\right]-l \theta_{i} v_{i}+\sqrt{2 a e s \theta_{i}} \\
& \frac{l}{2 \sqrt{\bar{r}-l\left(p+v_{i}\right)}} \\
& =\frac{\theta_{i}}{\sqrt{\bar{r}-l\left(p+v_{i}\right)}}\left[F\left(v_{i}\right)+l \sqrt{\frac{a e s}{2 \theta_{i}}}\right] \text {, } \\
& F\left(v_{i}\right)=\left[\bar{r}-l\left(p+v_{i}\right)\right]^{3 / 2}-l v_{i}\left[\bar{r}-l\left(p+v_{i}\right)\right]^{1 / 2} \\
& =\left[\bar{r}-l\left(p+v_{i}\right)\right]^{1 / 2}\left[\bar{r}-l\left(p+2 v_{i}\right)\right], \\
& 0 \leq v_{i} \leq \frac{\bar{r}}{l}-p . \\
& F^{\prime}\left(v_{i}\right)=\frac{-3}{2} l\left[\bar{r}-l\left(p+v_{i}\right)\right]^{1 / 2}-l\left[\bar{r}-l\left(p+v_{i}\right)\right]^{1 / 2}+\frac{l^{2} v_{i}}{2}\left[\bar{r}-l\left(p+v_{i}\right)\right]^{-1 / 2} \\
& =\frac{l}{2 \sqrt{\bar{r}-l\left(p+v_{i}\right)}}\left[l v_{i}-5\left(\bar{r}-l\left(p+v_{i}\right)\right)\right]=\frac{3 l^{2}}{\sqrt{\bar{r}-l\left(p+v_{i}\right)}}\left[v_{i}-\frac{5}{6}\left(\frac{\bar{r}}{l}-p\right)\right], \quad 0 \leq v_{i} \leq \frac{\bar{r}}{l}-p, \\
& F^{\prime \prime}\left(v_{i}\right)=3 l^{2}\left(\frac{\sqrt{\bar{r}-l\left(p+v_{i}\right)}+\left[v_{i}-(5 / 6)(\bar{r} / l-p)\right] \cdot\left(l / 2 \sqrt{\bar{r}-l\left(p+v_{i}\right)}\right)}{\bar{r}-l\left(p+v_{i}\right)}\right) \\
& =3 l^{3} \cdot \frac{2\left[\bar{r} / l-\left(p+v_{i}\right)\right]+\left[v_{i}-(5 / 6)(\bar{r} / l-p)\right]}{2 \sqrt{\bar{r}-l\left(p+v_{i}\right)} \cdot\left[\bar{r}-l\left(p+v_{i}\right)\right]}=\frac{3 l^{2}\left[(7 / 6)(\bar{r} / l-p)-v_{i}\right]}{2 \sqrt{\bar{r}-l\left(p+v_{i}\right)} \cdot\left[\bar{r} / l-p-v_{i}\right]}>0 .
\end{aligned}
$$

$\left.\operatorname{Using}\left(d \pi_{i} / d v_{i}\right)\right|_{v=v_{i}^{*}}=0$ and calculating (11) and (12), it yields that

$$
\begin{aligned}
\pi_{i}^{*}= & \pi_{i}\left(v_{i}^{*}\right)=\left.2\left[\frac{\bar{r}-l\left(p+v_{i}^{*}\right)}{l}\right] \frac{d \pi_{i}}{d v_{i}}\right|_{v_{i}=v_{i}^{*}}+\pi_{i}\left(v_{i}^{*}\right) \\
= & \theta_{i}\left[\bar{r}-l\left(p+2 v_{i}^{*}\right)\right] \cdot 2 \cdot \frac{\bar{r}-l\left(p+v_{i}^{*}\right)}{l} \\
& +v_{i}^{*} \theta_{i}\left[\bar{r}-l\left(p+v_{i}^{*}\right)\right] \\
= & \theta_{i}\left[\bar{r}-l\left(p+v_{i}^{*}\right)\right]\left[2 \frac{\bar{r}}{l}-2\left(p+2 v_{i}^{*}\right)+v_{i}^{*}\right] \\
= & 2 \theta_{i}\left[\bar{r}-l\left(p+v_{i}^{*}\right)\right]\left[\frac{\bar{r}}{l}-p-\frac{3}{2} v_{i}^{*}\right]
\end{aligned}
$$

and hence

$$
v_{i}^{*}<\frac{2}{3}\left(\frac{\bar{r}}{l}-p\right) .
$$

From (15), we can obtain

$$
F^{\prime}\left(v_{i}\right)<0 \quad \text { if and only if } v_{i}<\frac{5}{6}\left(\frac{\bar{r}}{l}-p\right) .
$$

The diagram obtained from (13), (15), (16), and (18) is shown in Figure 1.

\section{The Properties of Optimal Solution $v_{i}^{*}$ of (11)}

Eqs. (13) and (14) showed that $v_{i}^{*}$ must satisfy

$$
\begin{aligned}
0= & \left.\frac{d \pi_{i}}{d v_{i}}\right|_{v=v_{i}^{*}}=F\left(v_{i}^{*}\right)+l \sqrt{\frac{a e s}{2 \theta_{i}}} \\
= & {\left[\bar{r}-l\left(p+v_{i}^{*}\right)\right]^{3 / 2}-l v_{i}^{*}\left[\bar{r}-l\left(p+v_{i}^{*}\right)\right]^{1 / 2} } \\
& +l \sqrt{\frac{a e s}{2 \theta_{i}}}
\end{aligned}
$$

and hence

$$
0=\lim _{e \rightarrow 0}\left[F\left(v_{i}^{*}\right)+l \sqrt{\frac{a e s}{2 \theta_{i}}}\right]=F\left(v_{i}^{*}\right) .
$$

This implies that

$$
\lim _{e \rightarrow 0} v_{i}^{*}=\frac{1}{2}\left(\frac{\bar{r}}{p}-p\right) \quad \text { (c.f. Figure 1). }
$$

5.1. The Changing Effect of the Optimal Gross Profit $v_{i}^{*}$ of Retailer $i$ with respect to Price $p$. We viewed $v_{i}^{*}$ as a function of $p$ (parameters except for $p$ remain unchanged) and 


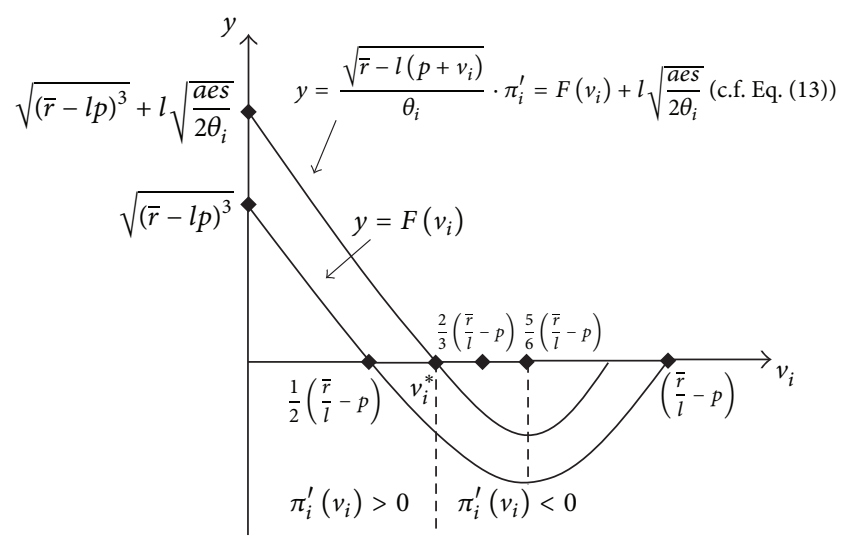

FIgURE 1: Optimal gross profit $v_{i}^{*}$ of retailer $i$.

considered the partial differential of (20) with respect to $p$ (denoted by $v_{i}^{* \prime}(p)$ ) to obtain

$$
\begin{gathered}
\frac{-3}{2} l\left[\bar{r}-l\left(p+v_{i}^{*}\right)\right]^{1 / 2}\left[1+v_{i}^{* \prime}(p)\right] \\
-l v_{i}^{* \prime}(p)\left[\bar{r}-l\left(p+v_{i}^{*}\right)\right]^{1 / 2} \\
-l v_{i}^{*} \frac{-l\left[1+v_{i}^{* \prime}(p)\right]}{2 \sqrt{\bar{r}-l\left(p+v_{i}^{*}\right)}}=0 ;
\end{gathered}
$$

that is,

$$
\begin{aligned}
- & 3 l\left[\bar{r}-l\left(p+v_{i}^{*}\right)\right]\left[1+v_{i}^{* \prime}(p)\right] \\
- & 2 l v_{i}^{* \prime}(p)\left[\bar{r}-l\left(p+v_{i}^{*}\right)\right]+l^{2} v_{i}^{*}\left[1+v_{i}^{* \prime}(p)\right] \\
= & 0, \\
0= & v_{i}^{* \prime}(p) \cdot 3 l\left[\bar{r}-l\left(p+v_{i}^{*}\right)\right]+2 l\left[\bar{r}-l\left(p+v_{i}^{*}\right)\right] \\
- & l^{2} v_{i}^{*}=-3 l\left[\bar{r}-l\left(p+v_{i}^{*}\right)\right]+l^{2} v_{i}^{*} .
\end{aligned}
$$

This implies that

$$
\begin{aligned}
v_{i}^{* \prime}(p) & =\frac{-3\left[\bar{r}-l\left(p+v_{i}^{*}\right)\right]+l v_{i}^{*}}{5\left[\bar{r}-l\left(p+v_{i}^{*}\right)\right]-l v_{i}^{*}} \\
& =\frac{4 v_{i}^{*}-3(\bar{r}-l p)}{-6 v_{i}^{*}-5(\bar{r}-l p)} \\
& =\frac{4\left[(3 / 4)(\bar{r} / l-p)-v_{i}^{*}\right]}{6\left[(5 / 6)(\bar{r} / l-p)+v_{i}^{*}\right]} .
\end{aligned}
$$

Thus

$$
v_{i}^{* \prime}(p)>0 \quad \text { if and only if } v_{i}^{*}<\frac{3}{4}\left(\frac{\bar{r}}{l}-p\right) .
$$

It means that $v_{i}^{*}$ is smaller than the gross profit upper limit $(\bar{r} / l-p)$ of $75 \%, \forall i=1,2, \ldots, n$.

The upper limit of product gross profit refers to the phenomenon in which nobody is willing to purchase the products when retailers increase the unit price to $(\bar{r}-p)$. According to (26), the condition for individual retailers' optimal gross profit $v_{i}^{*}$ to increase with the per unit purchase price $p$ is that the current optimal gross profit $v_{i}^{*}$ must be less than $75 \%$ of the aforementioned gross profit upper limit $(\bar{r}-p)$. Thus, an individual retailers' optimal gross profit $v_{i}^{*}$ of less than $75 \%$ of the gross profit upper limit $(\bar{r}-p)$ and a greater distance between these two items lead to a greater increase rate $v_{i}^{* \prime}(p)$ in $v_{i}^{*}$. This rate increases with the per unit purchase price $p$.

5.2. The Changing Effect of $v_{i}^{*}$ with respect to the Unit Product Prepayment $e$. The variable $v_{i}^{*}$ is viewed as the function of $e$. Considering the partial differential of (20) with respect to $e$, it yields that

$$
\begin{aligned}
0= & \frac{-3}{2} l\left[\bar{r}-l\left(p+v_{i}^{*}\right)\right]^{1 / 2} \cdot v_{i}^{* \prime}(e) \\
-l v_{i}^{* \prime}(e)\left[\bar{r}-l\left(p+v_{i}^{*}\right)\right]^{1 / 2}-l^{2} v_{i}^{*} & \\
\cdot \frac{v_{i}^{* \prime}(p)}{2 \sqrt{\bar{r}-l\left(p+v_{i}^{*}\right)}}+\frac{1}{2} \sqrt{\frac{a s}{2 \theta_{i} \cdot e}}, & \\
& \forall i=1,2, \ldots, n .
\end{aligned}
$$

This implies that

$$
\begin{aligned}
& v_{i}^{* \prime}(e)\left(\frac{3}{2} l\left[\bar{r}-l\left(p+v_{i}^{*}\right)\right]^{1 / 2}+l\left[\bar{r}-l\left(p+v_{i}^{*}\right)\right]^{1 / 2}\right. \\
& \left.+\frac{l^{2} v_{i}^{*}}{2 \sqrt{\bar{r}-l\left(p+v_{i}^{*}\right)}}\right)=\frac{1}{2} \sqrt{\frac{a s}{2 \theta_{i} \cdot e}}
\end{aligned}
$$

that is,

$$
\begin{aligned}
v_{i}^{* \prime} & (e) \frac{1}{\sqrt{\bar{r}-l\left(p+v_{i}^{*}\right)}}\left(5\left[\bar{r}-l\left(p+v_{i}^{*}\right)\right]+l v_{i}^{*}\right) \\
= & \frac{1}{l} \sqrt{\frac{a s}{2 \theta_{i} \cdot e}}
\end{aligned}
$$

and hence

$$
\begin{aligned}
v_{i}^{* \prime}(e)= & \left(5\left[\bar{r}-l\left(p+v_{i}^{*}\right)\right]+l v_{i}^{*}\right)^{-1} \\
& \cdot \sqrt{\left[\bar{r}-l\left(p+v_{i}^{*}\right)\right]} \cdot \frac{1}{l} \sqrt{\frac{a s}{2 \theta_{i} \cdot e}}>0 .
\end{aligned}
$$

This means that when $e$ is reduced, $v_{i}^{*}$ will decrease and therefore

$$
\frac{1}{2}\left(\frac{\bar{r}}{l}-p\right)=\lim _{e \rightarrow 0^{+}} v_{i}^{*}(e)<v_{i}^{*}(e)<\lim _{e \rightarrow p^{-}} v_{i}^{*}(e)
$$

(c.f. Eq. (30) and Figure 1). 
This equation shows that the optimal gross profit $v_{i}^{*}$ of all individual retailers' increases with the advance payment of per unit purchase $e$; the increase rate (i.e., $\left.v_{i}^{* \prime}(e)\right)$ and various parameter value relationships are expressed in (30).

5.3. The Changing Effect of $v_{i}^{*}$ with respect to the Retailer Market Share $\theta_{i}$. When $\theta_{i}$ becomes smaller, the curve $y=$ $f\left(v_{i}\right)+l \sqrt{a e s / 2 \theta_{i}}$ in Figure 1 moves upward. Consequently, intersection $v_{i}^{*}$ of the curve and the horizontal axis becomes larger. This indicates that

$$
v_{i}^{* \prime}(\theta)<0 .
$$

In reality, considering the partial differential of (20) with respect to $\theta$, it yields

$$
F^{\prime}\left(v_{i}^{*}\right) \cdot v_{i}^{* \prime}(\theta)+l \sqrt{\frac{a e s}{2}} \cdot\left(-\frac{1}{2}\right) \theta_{i}^{-3 / 2}=0
$$

and hence

$$
\begin{aligned}
v_{i}^{* \prime}(\theta) & =\frac{l \sqrt{a e s}}{2 F^{\prime}\left(v_{i}^{*}\right) \sqrt{\theta^{3}}} \\
& <0\left(\text { Figure } 1 \text { showed that } F^{\prime}\left(v_{i}^{*}\right)<0\right) .
\end{aligned}
$$

Together with (4), (32), and (34), it leads to

$$
v_{1}^{*} \leq v_{2}^{*} \leq \cdots \leq v_{n}^{*} .
$$

This indicated that retailers with high market share $\theta_{i}$ have low optimal retail price $v_{i}^{*}$.

5.4. The Changing Effect of $v_{i}^{*}$ with respect to the Fixed Transaction Cost $a$. We viewed $v_{i}^{*}$ in (20) as the function of parameters $a$ (other parameters remain unchanged). Copying the discussion of (26), it leads to

$$
v_{i}^{* \prime}(a)=\frac{\sqrt{e s /\left(2 \theta_{i} \cdot a\right)} \cdot \sqrt{\bar{r}-l\left(p+v_{i}^{*}\right)}}{5 \sqrt{\bar{r}-l\left(p+v_{i}^{*}\right)}+l v_{i}^{*}}>0 .
$$

This equation shows that the optimal gross profit $v_{i}^{*}$ of any seller increases with its order preparation cost $a$. In other words, sellers must increase their selling price $\left(p+v_{i}^{*}\right)$ when retailers increase their order preparation cost $a$, resulting in an increase in sellers' optimal gross profit $v_{i}^{*}(a)$; the increase rate (i.e., $\left.v_{i}^{* \prime}(a)\right)$ is expressed in (36).

5.5. The Changing Effect of $v_{i}^{*}$ with respect to the Interest $s$. We viewed $v_{i}^{*}$ in (20) as a function of parameter $s$ (other parameters remain unchanged). Copying the discussion of (26), it leads to

$$
v_{i}^{* \prime}(s)=\frac{\sqrt{a e} \cdot \sqrt{\bar{r}-l\left(p+v_{i}^{*}\right)}}{\sqrt{2 \theta_{i} \cdot s}\left[s \sqrt{\bar{r}-l\left(p+v_{i}^{*}\right)}+l v_{i}^{*}\right]}>0 .
$$

This equation shows that when the retailers' holding cost $s$ per unit time during the acquisition of unit funds (i.e., interest rate) increases, they must increase their selling price $\left(p+v_{i}^{*}\right)$. This causes their optimal gross profit $v_{i}^{*}$ to increase with $s$; the increase rate (i.e., $\left.v_{i}^{* \prime}(s)\right)$ is expressed in (37).
5.6. The Changing Effect of $v_{i}^{*}$ with respect to the Demand Rate Upper Limit $\bar{r}$. When $\bar{r}$ increases (other parameters remain unchanged), Figure 1 shows that the two curves in the diagram moved toward the upper level and, therefore, $v_{i}^{*}$ increased. Considering the partial differential of (20) with respect to $\bar{r}$, it leads to

$$
v_{i}^{* \prime}(\bar{r})=\frac{3(\bar{r}-l p)-4 l v_{i}^{*}}{l\left[5(\bar{r}-l p)-6 l v_{i}^{*}\right]}>0 .
$$

This equation shows that an increase in the upper limit of commodity market demand $\bar{r}$ causes the whole demand function curve of commodities to shift upward, which in turn increases the optimal gross profit $v_{i}^{*}(\bar{r})$ of any retail vendor. The increase rate of the optimal gross profit (i.e., $\left.v_{i}^{* \prime}(\bar{r})\right)$ is expressed in (38).

5.7. The Changing Effect of $v_{i}^{*}$ with respect to the Demand Function Slope l. We viewed $v_{i}^{*}$ in (20) as a function of parameter $l$. Considering the partial differential of (20) with respect to $l$, it yields

$$
\begin{aligned}
0= & \frac{3}{2} \sqrt{\bar{r}-l\left(p+v_{i}^{*}\right)} \cdot\left[-\left(p+v_{i}^{*}\right)-l v_{i}^{* \prime}\right] \\
& -\left(v_{i}^{*}+l v_{i}^{* \prime}\right) \sqrt{\bar{r}-l\left(p+v_{i}^{*}\right)}-\frac{1}{2} l v_{i}^{*} \\
& \cdot \frac{-\left(p+v_{i}^{*}\right)-l v_{i}^{* \prime}}{\sqrt{\bar{r}-l\left(p+v_{i}^{*}\right)}} .
\end{aligned}
$$

Multiplying the factor $\sqrt{\bar{r}-l\left(p+v_{i}^{*}\right)}$ to each term of the above equation, it leads to

$$
\begin{aligned}
v_{i}^{* \prime}( & \left.\frac{5}{2} l\left[\bar{r}-l\left(p+v_{i}^{*}\right)\right]-\frac{1}{2} l^{2} v_{i}^{*}\right) \\
= & \frac{-3}{2}\left[\bar{r}-l\left(p+v_{i}^{*}\right)\right]\left(p+v_{i}^{*}\right) \\
& -v_{i}^{*}\left[\bar{r}-\frac{3}{2} \cdot l\left(p+v_{i}^{*}\right)\right]
\end{aligned}
$$

and hence

$$
\begin{aligned}
v_{i}^{* \prime} \cdot 5 l & {\left[\bar{r}-l\left(p+\frac{6}{5} v_{i}^{*}\right)\right] } \\
= & -3\left[\bar{r}-l\left(p+v_{i}^{*}\right)\right]\left(p+v_{i}^{*}\right) \\
& -v_{i}^{*}\left[2 \bar{r}-3 l\left(p+v_{i}^{*}\right)\right] \\
= & 6 l v_{i}^{* 2}+\left(9 l p-5 \bar{r} v_{i}^{*}\right)-3\left(\bar{r} p+l p^{2}\right) .
\end{aligned}
$$

Since $5 l\left[\bar{r}-l\left(p+(6 / 5) v_{i}^{*}\right)\right]$ is positive (c.f. Figure 1)

$$
v_{i}^{* \prime}(l)>0
$$

if and only if $6 l v_{i}^{* 2}+\left(9 l p-5 \bar{r} v_{i}^{*}\right)-3\left(\bar{r} p+l p^{2}\right)<0$. 
This implies that

$$
\begin{aligned}
& v_{i}^{* \prime}(l)>0 \\
& \text { if and only if } v_{i}^{*}>\frac{-(9 l p-5 \bar{r})+\sqrt{(9 l p-5 \bar{r})^{2}+72 l\left(\bar{r} p-l p^{2}\right)}}{12 l} \text {. }
\end{aligned}
$$

This equation shows that when the absolute value of the negative slope for the commodity market demand function $l(l>0)$ increases, whether the retailers' optimal gross profit $v_{i}^{*}$ increases should still be judged based on the relative values of other parameters. The judgment criteria are expressed in (43).

\section{Conclusions}

We represented the optimal retailer product pricing problem in supplier's partial absorption of retailer inventory costs into a mathematical model that can be specifically discussed. The optimal retail price in this model showed that regardless of the parameters in the model or the number of retailers, each retailer's optimal retail price was between $1 / 2$ (50\%) and $2 / 3(66.67 \%)$ times that of the gross profit upper limit. This indicated the retail price margin selected by retailers does not exceed $16.67 \%$ times (that is, between $66.67 \%$ and $50 \%$ ) that of the gross profit upper limit. In particular, the higher the market share is, the closer the optimal retail price is to $50 \%$ of the gross margin ceiling. In turn, optimal retail price of the lower market share is closer to $66.67 \%$ of the gross margin ceiling.

To expand the applicability of this model, we further demonstrated a rate of change mathematical model for the changes in optimal retail price caused by variations in each parameter, which yielded various properties. The results of this study showed that

(a) when a retailer sells goods, the lower the delayed payment that it pays the supplier, the closer the retailer's optimal gross profit to $2 / 3$ of the gross profit's upper limit. By contrast, the higher the delayed payment, the closer the optimal gross profit to $1 / 2$ of the optimal gross profit's upper limit.

(b) when retailers' purchase price increases for products that yield high gross profits (products that generate gross profits that exceed $75 \%$ of the gross profit upper limit) the optimal retail price decreases.

(c) when retailers' purchase price increases for products that yield low gross profits, the optimal retail price increases. The application of these results on the frequently encountered problem of whether retailers should increase or decrease retail prices when product purchase price increases has practical value.

Thus, comparisons of optimal retail prices for retailers with different market shares in this study are critical topics related to sales practices.

By using these research results, retailers can rapidly adjust product prices according to market change and sales requirements. Compared with complex analysis models previously used for calculating optimal policies, which are seldom used in actual practice [23], the results of this study are convenient to apply in actual practice. Furthermore, these results can help suppliers decide their wholesale price levels and establish levels for absorbing retailers' inventory costs. Future studies must further expand these research results.

\section{Conflicts of Interest}

The author declares that there are no financial or other conflicts of interest.

\section{Acknowledgments}

This work is supported in part by the Ministry of Science and Technology of the Republic of China under Grant NSC1022410-H-130-021.

\section{References}

[1] R. O. C. Ministry of Economic Affairs, "2016 SMEs Important Statistics," http://www.moeasmea.gov.tw/ct.asp?xItem= 14250\&amp;ctNode=689\&amp;mp=1, 2016.

[2] L. Zavanella and S. Zanoni, "A one-vendor multi-buyer integrated production-inventory model: The 'Consignment Stock' case," International Journal of Production Economics, vol. 118, no. 1, pp. 225-232, 2009.

[3] D. Battini, A. Grassi, A. Persona, and F. Sgarbossa, "Consignment stock inventory policy: Methodological framework and model," International Journal of Production Research, vol. 48, no. 7, pp. 2055-2079, 2010.

[4] C. Srinivas and C. S. P. Rao, "Optimization of supply chains for single-vendor-multibuyer consignment stock policy with genetic algorithm," The International Journal of Advanced Manufacturing Technology, vol. 48, no. 1-4, pp. 407-420, 2010.

[5] J. Yu, B. R. Sarker, Q. Duan, and B. Wu, "Single-manufacturer, multi-retailer consignment policy for retailers generalized demand distributions," Journal of the Operational Research Society, vol. 63, no. 12, pp. 1708-1719, 2012.

[6] M. Ben-Daya, E. Hassini, M. Hariga, and M. M. AlDurgam, "Consignment and vendor managed inventory in single-vendor multiple buyers supply chains," International Journal of Production Research, vol. 51, no. 5, pp. 1347-1365, 2013.

[7] M. A. Hariga and A. Al-Ahmari, "An integrated retail space allocation and lot sizing models under vendor managed inventory and consignment stock arrangements," Computers \& Industrial Engineering, vol. 64, no. 1, pp. 45-55, 2013.

[8] B. Sarkar, "A production-inventory model with probabilistic deterioration in two-echelon supply chain management," Applied Mathematical Modelling, vol. 37, no. 5, pp. 3138-3151, 2013.

[9] A. K. Singh, T. Hasan, and G. Krisha, "An approach of swarm intelligence for various consignment stock models," International Journal of Innovative Technology and Research, vol. 4, pp. 2864-2870, 2016.

[10] S. M. S. Islam, M. A. Hoque, and N. Hamzah, "Single-supplier single-manufacturer multi-retailer consignment policy for retailers' generalized demand distributions," International Journal of Production Economics, vol. 184, pp. 157-167, 2017.

[11] S. K. Zahran and M. Y. Jaber, "Investigation of a consignment stock and a traditional inventory policy in a three-level supply 
chain system with multiple-suppliers and multiple-buyers," Applied Mathematical Modelling: Simulation and Computation for Engineering and Environmental Systems, vol. 44, pp. 390408, 2017.

[12] S. K. Goyal, "Determination of Optimum Production Quantity for a Two-Stage Production System," Operational Research Quarterly (1970-1977), vol. 28, no. 4, pp. 865-870, 1977.

[13] S. K. Goyal, "An integrated inventory model for a singles upplier-single customer problem," International Journal of Production Research, vol. 15, no. 1, pp. 107-111, 1977.

[14] S. K. Goyal, "A joint economic-lot-size model for purchaser and vendor: a comment," Decision Sciences, vol. 19, no. 1, pp. 236241, 1988.

[15] S. K. Goyal and Y. P. Gupta, "Integrated inventory models: The buyer-vendor coordination," European Journal of Operational Research, vol. 41, no. 3, pp. 261-269, 1989.

[16] A. Banerjee, "A joint economic-lot-size model for purchaser and vendor," Decision Sciences, vol. 17, no. 3, pp. 292-311, 1986.

[17] R. M. Hill, “The single-vendor single-buyer integrated production-inventory model with a generalised policy," European Journal of Operational Research, vol. 97, no. 3, pp. 493-499, 1997.

[18] R. M. Hill, “The optimal production and shipment policy for the singke-vendor singlebuyer integrated production-inventory problem," International Journal of Production Research, vol. 37, no. 11, pp. 2463-2475, 1999.

[19] S. K. Goyal, "On improving the single-vendor single-buyer integrated production inventory model with a generalized policy," European Journal of Operational Research, vol. 125, no. 2, pp. 429-430, 2000.

[20] M. Ben-Daya and M. Hariga, "Integrated single vendor single buyer model with stochastic demand and variable lead time," International Journal of Production Economics, vol. 92, no. 1, pp. 75-80, 2004.

[21] M. A. Hoque and S. K. Goyal, "A heuristic solution procedure for an integrated inventory system under controllable lead-time with equal or unequal sized batch shipments between a vendor and a buyer," International Journal of Production Economics, vol. 102, no. 2, pp. 217-225, 2006.

[22] A. Nalça, H. Süral, and Y. Gerchak, "Economic manufacturing quantities of components in supply chains," International Journal of Inventory Research, vol. 2, no. 1/2, p. 44, 2013.

[23] G. Valentini and L. Zavanella, "The consignment stock of inventories: Industrial case and performance analysis," International Journal of Production Economics, vol. 81-82, pp. 215-224, 2003.

[24] M. Braglia and L. Zavanella, "Modelling an industrial strategy for inventory management in supply chains: The 'Consignment Stock' case," International Journal of Production Research, vol. 41, no. 16, pp. 3793-3808, 2003.

[25] S. Zanoni and R. W. Grubbstrom, "A note on an industrial strategy for stock management in supply chains: Modelling and performance evaluation," International Journal of Production Research, vol. 42, no. 20, pp. 4421-4426, 2004.

[26] C. Srinivas and C. S. P. Rao, "An improved consignment stock policy under stochastic lead times for effective inventory management in supply chains," in Proceedings of the Proceedings 2004 IEEE International Engineering Management Conference: Innovation and Entrepreneurship for Sustainable Development, IEMC 2004, pp. 1222-1225, sgp, October 2004.

[27] A. Persona, A. Grassi, and M. Catena, "Consignment stock of inventories in the presence of obsolescence," International Journal of Production Research, vol. 43, no. 23, pp. 4969-4988, 2005.
[28] R. M. Hill and M. Omar, "Another look at the single-vendor single-buyer integrated production-inventory problem," International Journal of Production Research, vol. 44, no. 4, pp. 791800, 2006.

[29] B. C. Giri and S. Bardhan, "A vendor-buyer JELS model with stock-dependent demand and consigned inventory under buyer's space constraint," Operational Research, vol. 15, no. 1, pp. 79-93, 2015.

[30] M. Gümüş, E. M. Jewkes, and J. H. Bookbinder, "Impact of consignment inventory and vendor-managed inventory for a two-party supply chain," International Journal of Production Economics, vol. 113, no. 2, pp. 502-517, 2008.

[31] J. Ru and Y. Wang, "Consignment contracting: who should control inventory in the supply chain?" European Journal of Operational Research, vol. 201, no. 3, pp. 760-769, 2010.

[32] J. Hwang and Y.-W. Wan, "A supplier-retailer supply chain with intermediate storage for batch ordering," International Journal of Production Economics, vol. 142, no. 2, pp. 343-352, 2013.

[33] S.-P. Wang, W. Lee, and C.-Y. Chang, "Modeling the consignment inventory for a deteriorating item while the buyer has warehouse capacity constraint," International Journal of Production Economics, vol. 138, no. 2, pp. 284-292, 2012.

[34] S. Islam and M. Hoque, "Single-vendor single-buyer optimal consignment policy with generic demand distribution by considering some realistic factors," International Journal of Operational Research, 2016, (in press).

[35] M. Dada and K. N. Srikanth, "Pricing policies for quantity discounts," Management Science, vol. 33, no. 10, pp. 1247-1252, 1987.

[36] P. N. Joglekar, "Note-Comments on "A Quantity Discount Pricing Model to Increase Vendor Profits", Management Science, vol. 34, no. 11, pp. 1391-1398, 1988.

[37] P. Joglekar and S. Tharthare, "The Individually Responsible and Rational Decision Approach to Economic Lot Sizes for One Vendor and Many Purchasers," Decision Sciences, vol. 21, no. 3, pp. 492-506, 1990.

[38] L. Lu, "A one-vendor multi-buyer integrated inventory model," European Journal of Operational Research, vol. 81, no. 2, pp. 312323, 1995.

[39] S. Viswanathan and R. Piplani, "Coordinating supply chain inventories through common replenishment epochs," European Journal of Operational Research, vol. 129, no. 2, pp. 277-286, 2001.

[40] Y. Y. Woo, S.-L. Hsu, and S. Wu, "An integrated inventory model for a single vendor and multiple buyers with ordering cost reduction," International Journal of Production Economics, vol. 73, no. 3, pp. 203-215, 2001.

[41] T. Boyac and G. Gallego, "Coordinating pricing and inventory replenishment policies for one wholesaler and one or more geographically dispersed retailers," International Journal of Production Economics, vol. 77, no. 2, pp. 95-111, 2002.

[42] T. Kim, Y. Hong, and S. Y. Chang, "Joint economic procurement-production-delivery policy for multiple items in a singlemanufacturer, multiple-retailer system," International Journal of Production Economics, vol. 103, no. 1, pp. 199-208, 2006.

[43] D. Battini, A. Gunasekaran, M. Faccio, A. Persona, and F. Sgarbossa, "Consignment stock inventory model in an integrated supply chain," International Journal of Production Research, vol. 48, no. 2, pp. 477-500, 2010.

[44] S. Bylka and P. Górny, "The consignment stock of inventories in coordinated model with generalized policy," Computers \& Industrial Engineering, vol. 82, pp. 54-64, 2015. 
[45] M. Hariga, M. Gumus, M. Ben-Daya, and E. Hassini, "Scheduling and lot sizing models for the single-vendor multi-buyer problem under consignment stock partnership," Journal of the Operational Research Society, vol. 64, no. 7, pp. 995-1009, 2013.

[46] Z. Chen and B. R. Sarker, "Integrated production-inventory and pricing decisions for a single-manufacturer multi-retailer system of deteriorating items under JIT delivery policy," The International Journal of Advanced Manufacturing Technology, vol. 89, no. 5-8, pp. 2099-2117, 2017.

[47] H. Siajadi, R. N. Ibrahim, and P. B. Lochert, "Joint economic lot size in distribution system with multiple shipment policy," International Journal of Production Economics, vol. 102, no. 2, pp. 302-316, 2006.

[48] H.-J. Chang and P.-Y. Chen, "An EOQ model with controllable selling rate," Asia-Pacific Journal of Operational Research, vol. 25, no. 2, pp. 151-167, 2008.

[49] R. Piplani and S. Viswanathan, "A model for evaluating supplierowned inventory strategy," International Journal of Production Economics, vol. 81-82, pp. 565-571, 2003.

[50] C. Srinivas and C. S. P. Rao, "Optimisation of supply chains for single vendor-multibuyer consignment stock policy under controllable lead time using genetic algorithm," International Journal of Manufacturing Research, vol. 2, no. 2, pp. 243-262, 2007.

[51] S. Wadhwa, M. Mishra, F. T. S. Chan, and Y. Ducq, "Effects of information transparency and cooperation on supply chain performance: A simulation study," International Journal of Production Research, vol. 48, no. 1, pp. 145-166, 2010.

[52] H. Yi and B. R. Sarker, "An operational policy for an integrated inventory system under consignment stock policy with controllable lead time and buyers' space limitation," Computers \& Operations Research, vol. 40, no. 11, pp. 2632-2645, 2013.

[53] H. Yi and B. R. Sarker, "An optimal consignment stock production and replenishment policy with controllable lead time," International Journal of Production Research, vol. 51, no. 21, pp. 6316-6335, 2013.

[54] S. Islam and M. Hoque, "An extension to single-manufacturer, multi-retailer consignment policy for retailers' generalized demand distributions," in Proceedings of the 5th Brunei International Conference on Engineering and Technology (BICET 2014), Bandar Seri Begawan, Brunei.

[55] B. R. Sarker, "Consignment stocking policy models for supply chain systems: a critical review and comparative perspective," International Journal of Production Economics, vol. 155, pp. 5267, 2014.

[56] C. Water, Inventory Control and Management, Wiley, New York, NY, USA, 1992. 


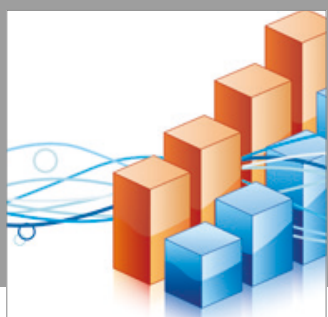

Advances in

Operations Research

vatersals

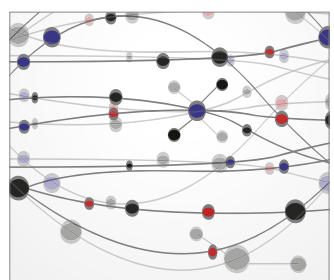

\section{The Scientific} World Journal
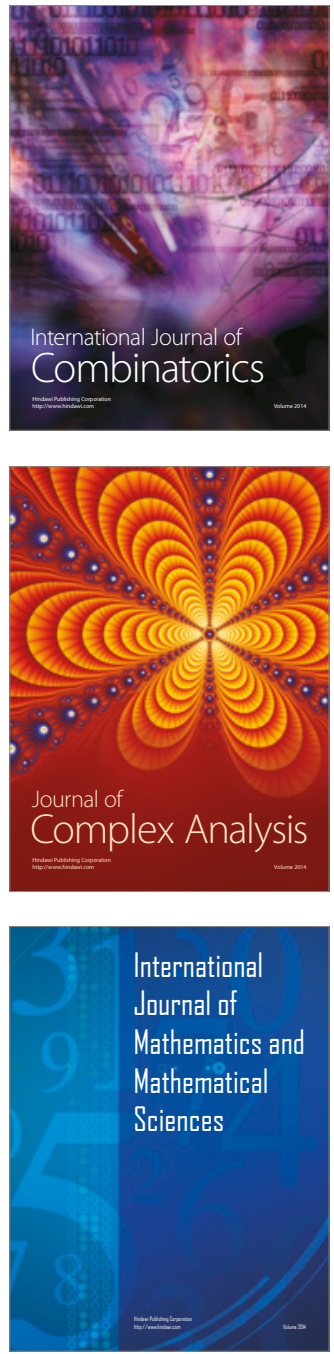
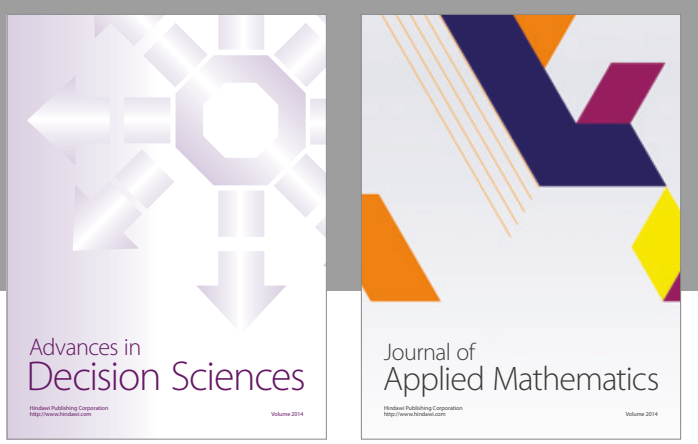

Algebra

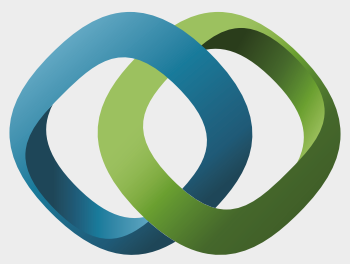

\section{Hindawi}

Submit your manuscripts at

https://www.hindawi.com
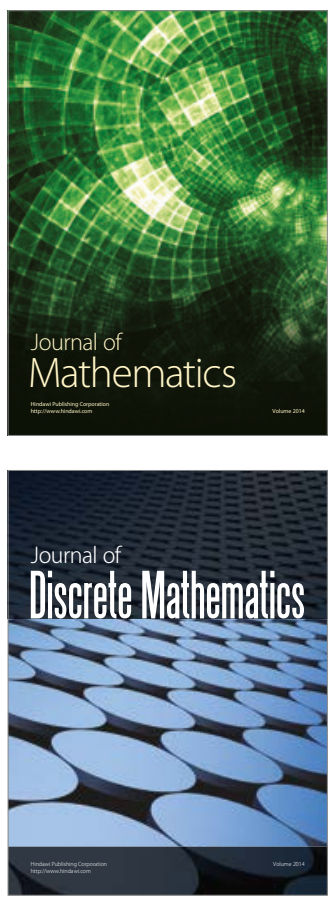

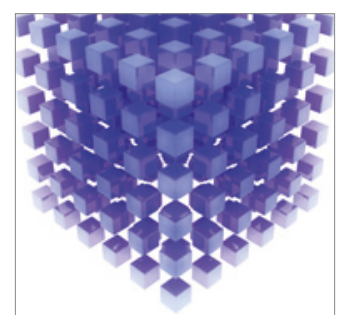

Mathematical Problems in Engineering
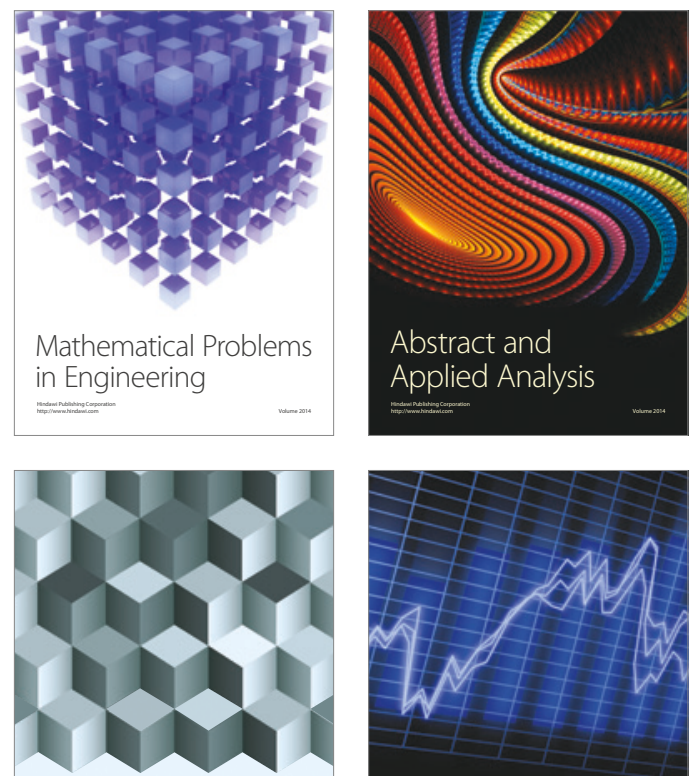

Journal of

Function Spaces

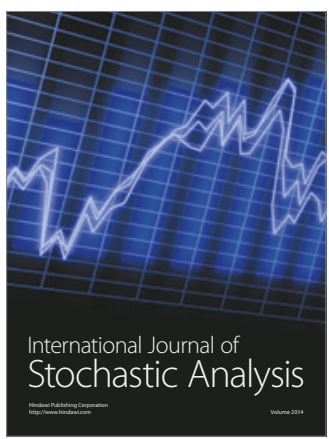

Probability and Statistics
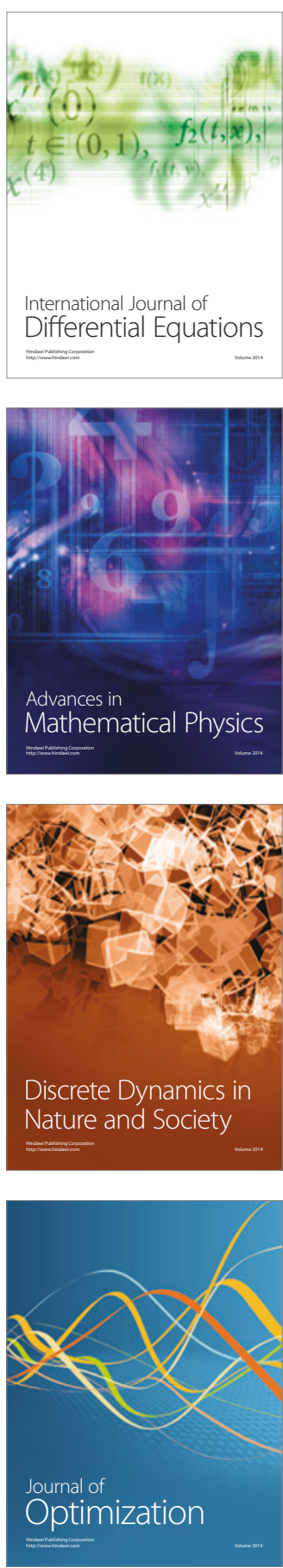